\title{
Approach towards an Expert Geoportal System
}

\author{
Umesh Chandra, $\mathrm{PhD}$ \\ Assistant Professor \\ Computer Science Department \\ Glocal University Saharanpur, India
}

\author{
Kamal Jain, $\mathrm{PhD}$ \\ Professor \\ Geomatics Enginneering \\ IIT Roorkee, \\ India
}

\begin{abstract}
The creation and management of geospatial data is always tedious requires huge budget, time and manual efforts. Therefore, the future of several important services including location-based services and disaster information system, which need geospatial data remains a matter of concern. Expert geoportal system (EGPS) is a tool based on a sophisticated approach for providing diverse geospatial services to a naive user without creating its own database (i.e. geospatial database). EGPS avoids the unnecessary efforts of creating and managing a database, which not only requires enormous amount of money but also manual efforts. This paper presents a step-by-step approach for designing and developing a system that uses third party authorized data and web services for providing diverse geospatial services to the naive user without creating and managing its own database.
\end{abstract}

\section{Keywords}

EGPS, geospatial services, geoportal, geographic information, geospatial database.

\section{INTRODUCTION}

Geographic information (GI) in particular is one of the most critical elements underpinning decision-making for many disciplines (Clinton, 1994, Gore, 1998, Longley et al., 1999, Williamson et al., 2003, Morales, 2004), including environment [Dispersion Modeling (Behera et al. (2011)) and Infrastructure [micro level planning (Bariar et al. (2004)]. In the past, maps were used for depicting the location of people and assets. However, in the recent times, a complex digital environment with sophisticated technology has evolved.

A geoportal is a web portal that provides diverse geospatial data on a single common platform. More specifically, geoportal may be defined as an internet or intranet entry point with tools for retrieving metadata, searching, visualising, downloading, and disseminating GI, and in some cases ordering GI services (i.e. facilitating GI commerce) (Maguire and Longley 2005, Tait 2005).

Geoportals provide diverse geospatial services to users through a general interface. Generally, geoportal developers create their own databases using traditional approaches, such as surveys, remote sensing, and capturing aerial images and data from some government and private agencies web services.

However, the traditional approach of developing a geoportal requires huge investment not only in the terms of money but also time and manual efforts. In addition, these geoportals are highly specific in nature, and if the user requires additional information, new services have to be developed from scratch.
Some of the existing geoportals are enlisted along with their data sources and associated services in Table 1. It is evident that geoportals use the shared diverse spatial data from different agencies for providing diverse services (Table 1). If these agencies deny or are unable to provide services, the future of geoportals may be directly affected (ESRI 2010, Oana et al. 2010, Chandra et al. 2013, Chandra et al. 2013 Gershenzon and Ash 2008).

EGPS overcomes the problems of existing systems by using a sophisticated approach and advanced technology. Developing a geoportal by creating own database is a traditional approach. However, EGPS is designed and developed using data and services that are already available on the web, which not only requires adequate knowledge of the framework used by the third party website but also requires sophisticated skills to utilise that data in a new platform and provide advanced services for better decision-making.

\subsection{Need of EGPS}

The sophisticated approach of EGPS solves two problems that are present in the existing system. First, it uses the data that is already available on the web, thus reducing the duplicity of data on the web. Second, it also enhances usability of the existing web data by transforming them into new information, which will help the naive user in better decision-making.

\subsection{Approach towards EGPS}

Designing and developing an EGPS that can resolve the problems of providing diverse geospatial services using online data and services, requires a highly sophisticated approach and complex architecture. This paper presents a step-by-step approach for developing a research methodology and compound architecture of EGPS, which can provide different types of geospatial services to their end users using third party web data.

\section{RESEARCH METHODOLOGY}

Web data have different dimensions and properties and are rapidly changing. Implementing a system that enhances the capability of the existing data in diverse web environment requires rethinking of the conventional approach such that it efficiently handles the existing information to provide better decision-making capabilities to the end user.

The present study derives and defines a step-by-step research methodology of a system that manages complex and varied data. According to the problems faced by the researchers, the entire research approach is divided into following four phases to develop a complex system that can resolve the meaningful data integration task: 
Table 1. Some Existing Geoportals and their Data Dependency for Specific Services

\begin{tabular}{|c|c|c|}
\hline Name & Data Sources & Services \\
\hline $\begin{array}{c}\text { Croatia Multipurpose Spatial } \\
\text { Information System Geoportal }\end{array}$ & Governmental bodies and Private sector & $\begin{array}{c}\text { Searching, ordering using } \\
\text { Geospatial data etc }\end{array}$ \\
\hline $\begin{array}{c}\text { Lithuanian Geographical Information } \\
\text { Infrastructure }\end{array}$ & $\begin{array}{c}10 \text { government institutions and State- } \\
\text { owned enterprises }\end{array}$ & Searching, Ordering etc. \\
\hline Romanian INIS Geoportal & $\begin{array}{c}\text { Centre for Geodesy, Cartography, } \\
\text { Photogrammetry and Remote Sensing }\end{array}$ & $\begin{array}{c}\text { Discover and select Geospatial } \\
\text { information resources. }\end{array}$ \\
\hline Kosmosnimki Geoportal & Earth Remote Sensing Data & $\begin{array}{c}\text { Searching, Ordering etc. } \\
\text { Bhuvan (Indian Geoportal) }\end{array}$ \\
\hline Karnataka Geoportal & Spatth Remote Sensing Data & Download data, Thematic \\
& & services \\
\hline
\end{tabular}

Table 2. Problem faced

\begin{tabular}{|c|c|c|c|}
\hline Step & Phase & Problem faced & Steps to Resolve Problem \\
\hline 1 & Phase 1 & $\begin{array}{l}\text { How to interact with the third party web data } \\
\text { providers. }\end{array}$ & $\begin{array}{l}\text { 1. Need of a general interface that interacts with } \\
\text { third party websites. } \\
\text { 2. User can also post a query on the third party } \\
\text { website using the interface provided by the } \\
\text { developed system. }\end{array}$ \\
\hline 2 & Phase 2 & $\begin{array}{l}\text { How to use the third party database without } \\
\text { violating their user agreements. }\end{array}$ & $\begin{array}{l}\text { Need of a module that can use the front end data } \\
\text { provided by the web forms without unauthorized } \\
\text { access of their database. }\end{array}$ \\
\hline 3 & Phase 3 & $\begin{array}{l}\text { How to tackle the diverse forms of data (text } \\
\text { and images). }\end{array}$ & $\begin{array}{l}\text { Need of specific adapter modules (classes) for each } \\
\text { problem with a slight change in the general } \\
\text { module. }\end{array}$ \\
\hline 4 & Phase 4 & $\begin{array}{l}\text { How totackle the rapidly changing third party } \\
\text { frontend framework. }\end{array}$ & Regular updates in EGPS required. \\
\hline
\end{tabular}

1) State the objective to be resolved,

2) Recognise relevant pieces of information on the internet (web data),

3) Process the third party information into proper formats

4) Resolve the objectives.

After recognising the challenges, all the technical and nontechnical difficulties that need to be resolved are defined before implementing a successful tool, which can effectively use the third party information, enhance their usability, and help in better decision-making. A four-phase tabular architecture, which explains all the problems faced and steps followed to resolve the difficulties in implementing a successful tool, and can resolve all the defined objectives is defined in Table 2.
After recognising the problems, a general methodology is developed, which can help in defining a system that resolves these challenges. The entire methodology of the EGPS system is divided into four phases:

In the first phase, a general web based interface is created for interacting with the third party website, shown by $[\mathrm{A}]$ in Figure 1. This interface consists of two parts: one for opening the third party web application and another for client application.

In the second phase, a specific adapter module is developed for individual web applications to save the front end data, including text and images, provided by the third party web application. This adapter module has to be redeveloped only when a change occurs in the third party website data including data format or style

In the third phase, the text data or images captured from the third party website is rearranged or classified in the client 
application to provide different geographic information system (GIS) functionalities for better decision-making.

In addition, client application has some more GIS functionalities, such as the facility of directly calling the map services (e.g. Google Earth APIs) ([B] in Figure 1) and published web services (i.e. weather forecasting services) ([C] in Figure 1) of the third party web service providers, thus offering interoperable combined results for better decisionmaking.

In the final phase, meaningful data is integrated in the client application after obtaining the data from diverse web resources.

\section{EGPS ARCHITECTURE}

'The architecture of a system defines its broad outlines and the precise mechanisms that draw a simplified structure in

front of the developers to create a flexible and reusable system' (Multitier Architecture, 2013).

Because geoportal is a web-based application, it has a simple client architecture; however, as shown in Figure 2, an expert geoportal has an extended client architecture with some additional capabilities and functionalities. Furthermore, the server is not a simple web server limited to a specific feature of requesting desired HTML/AJAX-based services but has improved interfaces for Google Map/Earth API and some newly defined services with a well-known database interface for the newly conceptualised temporary database. The extended architecture of EGPS is essential to interact with diverse web data provider, as shown by $\mathrm{A}, \mathrm{B}, \mathrm{C}, \mathrm{D}$, and $\mathrm{E}$ in Figure 2, to provide advance web services like Location based services, Weather forecasting, Vegetative growth analysis, Real time digital elevation model, and Image georeferencing to the user by digesting the information provide by these third party web data provider either singly or in combination as shown by i, ii, iii, iv and v in Figure 2.

\section{CONCLUSION}

First, the present work defines the problems persisting in the existing system. Second, it emphasises the reasons behind the need of EGPS. Third, it describes the challenges faced in defining and developing EGPS. Finally, this paper presents the entire methodology and provides a phase-by-phase definition of the architecture, from scratch to the final implementation of EGPS.

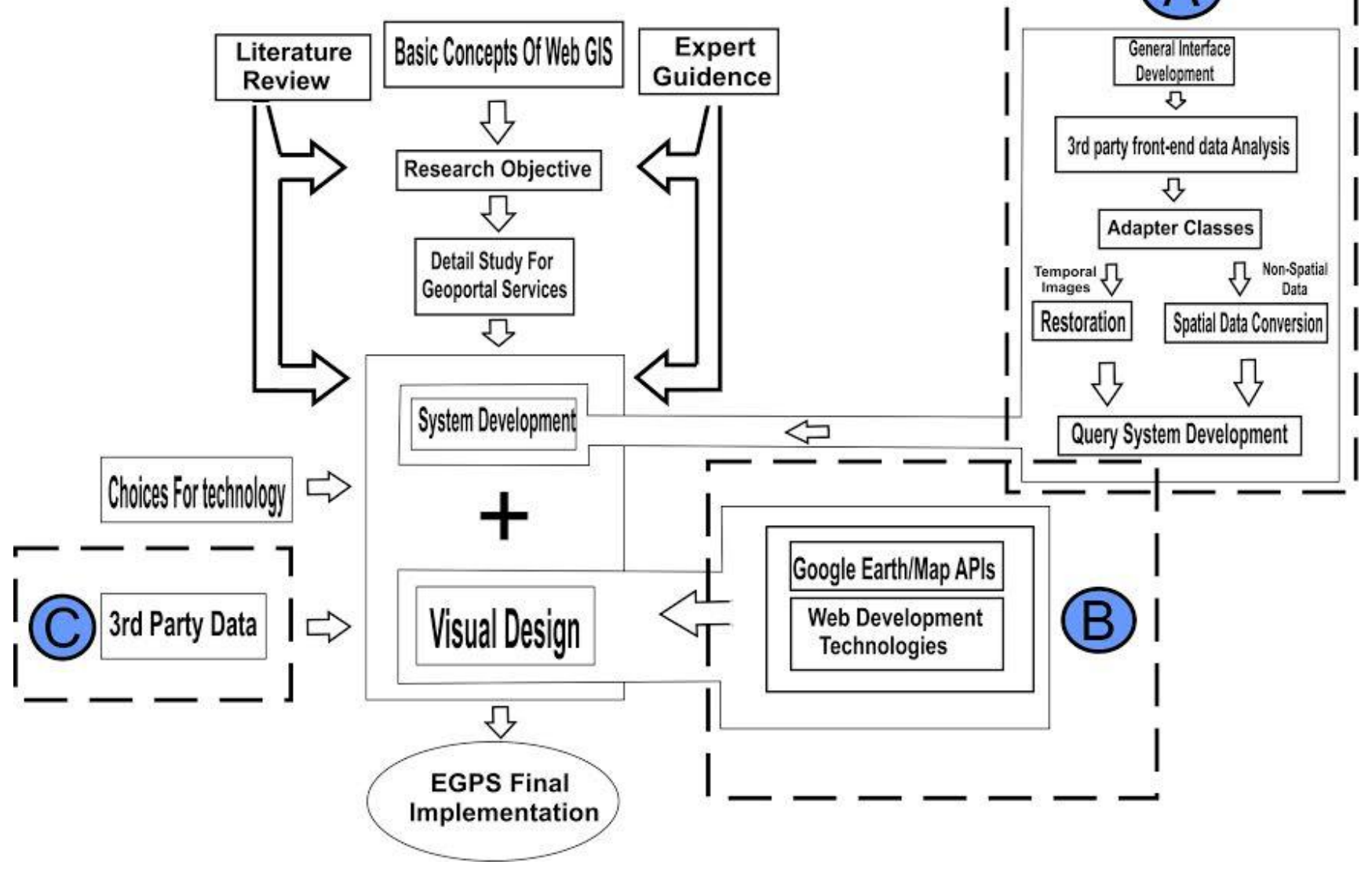

Figure 1. Methodology of EGPS 


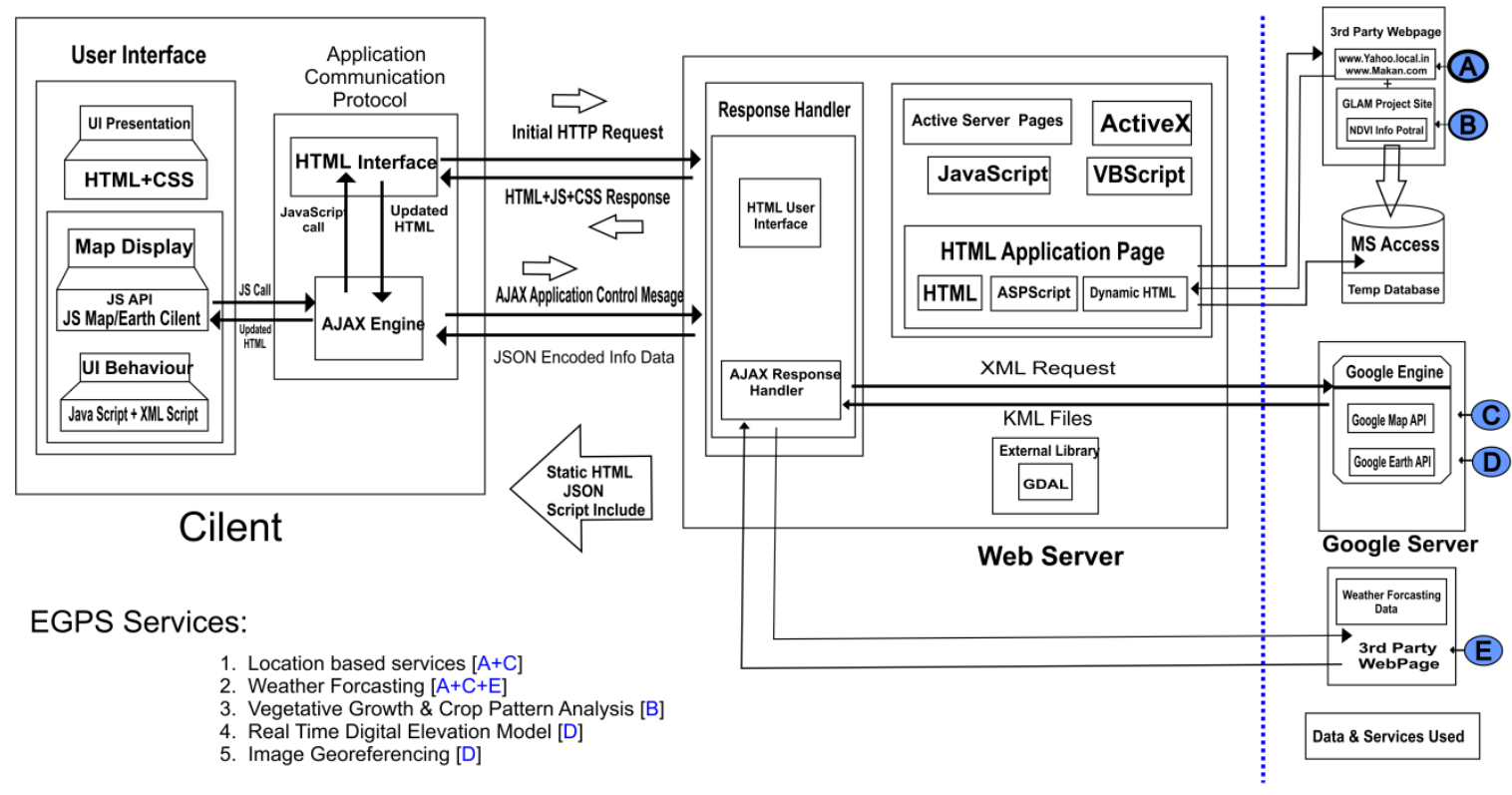

Figure 2. EGPS Architecture

\section{REFERENCES}

[1] Bariar, A., Gupta, R.D., and Prasad, S.C. 2004. Development of GIS based spatial data infrastructure for micro-level planning. Map World Forum. Hyderabad, India.

[2] Behera, S.N., Sharma, M., Dikshit, O., and Shukla, S.P. 2011. Development of GIS-aided Emission Inventory of Air Pollutants for an Urban Environment. Available from: http://www.intechopen.com/books/advanced-airpollution/development-of-gis-aided-emission-inventoryof-air-pollutants-for-an-urban-environment. Advanced Air Pollution, Dr. FarhadNejadkoorki (Ed.), ISBN: 978953-307-511-2, InTech, DOI: 10.5772/17008.

[3] Chandra, U., Jain, K., and Jain, S.K. 2013. Real Time Vegetation Analysis through Data Provided By GLAM Website. International Journal of Civil Engineering and Technology (IJCIET), Volume 4, Issue 1, JanuaryFeburary 2013, pp. 132-137, ISSN: 0976 - 6316.

[4] Chandra, U., Jain, K., and Jain, S.K. 2013. Mashup as a future of Geo-Portal.International Journal of Advanced Research in Engineering and Technology (IJARET), Volume 4, Issue 4, May- June 2013, pp. 2226, ISSN: $0976-6499$.

[5] Clinton, W. 1994. Coordinating geographic data acquisition and access to the National Spatial Data Infrastructure. Executive Order 12096, Federal Register 59, pp. 17671-4, Washington, DC, US.
[6] Esri Technology for INSPIRE. 2010. AnEsri ® White Paper.

[7] Gershenzon, V., and Ash, E. (2008).Experience of Russian GeoportalsBased on earth remote sensing data, SCANEX Research \& Development Center, Moscow Commission WG IV/5.

[8] Gore, A. (1998). The Digital Earth: understanding our planet in the 21st century, The Australian Surveyor, 43(2), pp. 89-91.

[9] Longley, P.A., Goodchild, M.F., Maguire, D.J., and Rhind, D.W. 1999. Geographic Information Systems, Second Edition. John Wiley \& Sons, New York.

[10] Maguire, D.J., and Longley, P.A. 2005. The emergence of geoportals and their role in spatial data infrastructures.

[11] Morales, J. (2004). Model-driven Design of Geoinformation Services. PhD-thesis, ITC Enschede.

[12] Oana, C., Smaranda, J.S., Zavate, L., Vasile, C., and Badea, A. 2009. ROEnvGeoPortal: A collaborative effort by and for the Romanian Environmental Sectors. Eleventh International Conference for Spatial Data Infrastructure.

[13] Williamson, I., Rajabifard, A., Feeney, and M-E. F. (Editors) 2003. Developing Spatial Data Infrastructures: From Concept to Reality. Taylor \& Francis, London, UK. 